wound being limited to the integuments covering the shin. There was a large pulpy mass covering the wound, through, or by the side of, which some blood was still oozing. This mass was chiefly coagulum. which I did not think it prudent to remove. The rest of the soft parts appeared to be uninjured, and as the bone-setter had placed the leg in a very good position, I merely removed his strips of adhesive plaister, substituting for them three or four thicknesses of wet lint, and bringing up the cushion on each side of the leg, I applied a couple of side splints outside, which I secured with a tape above and below the fracture. There were no bruises anywhere on the leg or thigh; and, notwithstanding the loss of blood, there was plenty of reaction. The pulse was about one hundred, soft and pleasant. He had had some brandy given him. I thought the case would do well, and with a caution to the friends that if gangrene should set in, it might be necessary to amputate in the middle of the leg, I left my patient for that day, sending him the following medicine :-

Bo Tincturæ opii 3 iij; spiritûs ammoniæ aromat. misturæ sennæ comp. 弓iv; aquæ menthæ piper. ad $\zeta x i j$. M. Sumat cochlearia ij ampla 4 tis horis.

I saw him again the next morning, Thursday, at about 10 I mention the hours, for the case was an affair of hours. His leg had not been disturbed. The lint I had placed over the wound, having been saturated with the oozing blood, was dry, hard, and firmly adherent as far as three or four inches above and below. I therefore did not disturb it, hoping that healthy suppuration would remove it as well as the subjacent coagulum. The temperature of the foot was natural and comfortable; the patient could move all his toes freely, particularly in the act of extension, so that little or no injury had been sustained by the muscles passing down the front of the leg. He could feel the slightest scratch on any part of the foot. I readjusted the two side splints, so as more efficiently to support the foot, and left him again, with the confident hope that all would go on well.

His bowels had been moved once.

The same evening at about 11 o'clock, I received a hasty message that "they were afraid mortification was taking place." This was incredible. I went immediately, reaching the man' residence, distant four miles from my own, at about midnight I was told that he had had a shivering fit in the middle of the day, and had been very restless ever since, complaining of much pain and aching over the whole leg and thigh; that one of his friends, finding that a finger with which the poor fellow had been scratching, or feeling of, the calf of the wounded leg, had been withdrawn wet, had lifted off the bed-clothes, and found an appearance on the outside of the knee which had alarmed him. I looked, and found that part gangrenous with several of the characteristic phlyctenæ upon it. The gangrenous patch extended round the knee, and on the outside, terminated at a point about the middle of the thigh. On the outside of the leg, it reached as far as the lint which I had placed over the wound, and which was now moist and loosened. The poor man in his restlessness, which could not be controlled, had rolled himself over on his left side, so that the lightly fixed cushion and splints had not prevented some displacement of the fractured bones. The march upwards of the gangrene, for it was spreading rapidly, was preceded by a margin about an inch and a half in breadth of less deeply discoloured skin. The calf of the leg and the underneath parts of the limb generally, where the gangrene was present, seemed most intensely affected, hypostatically, if I may use the phrase, although the outside of the limb was most extensively implicated. The foot and all the parts below the fracture, were entirely free from gangrenous taint. The pulse was 120 , with some volume, but very compressible. There were frequent eructations-if not exactly hiccups.

This was a truly alarming state of affairs-all in the middle of the night. Obviously amputation, even if it could have been performed at once, was inadmissible; for although the case was one of traumatic gangrene, strictly speaking, yet, begin ning and spreading exclusively above the wound, it could scarcely be looked upon as traumatic gangrene pure et simple. The line of demarcation must be waited for; therefore I was anxious for a second opinion, to pacify the friends as much as anything; for I could not see that it would be possible to save the man's life; I therefore sent off a man on horseback to fetch my friend Mr. Calthrop, of Withern, four miles off. Mr. Cal throp arrived at about half-past two. The gangrene had spread considerably, and was more intense. We agreed that nothing could be done, and left the poor fellow, after making him as comfortable as we could, at about half-past 3 A.M., Friday.

I saw him again at 10 A.Mr. He was pulseless. The whole of the thigh, inside and outside, and as far as the groin in front, was gangrenous, the slightly discoloured margin having encroached on the abdominal parietes. The foot was unaffected. He died at 11 .

At the inquest, which was held in the evening of the same day, I found, on showing the body to the coroner (himself a medical man) and jury, that although the whole of the leg above the wound was intensely gangrenous, the foot and other parts below it were entirely untainted.

REMarks. I think the case worthy of record. The points in it are: the commericement and rapid spread of gangrene above the wound which caused it; the anomaly that, if caused by absorption, the gangrene should have spread most rapidly on the outside of the limb; its commencement so soon after the accident, less than forty-eight hours; the immunity of the parts below the wound; the death of the patient in less than twenty-four hours after the shivering fit, which doubtless ushered in the gangrene.

Now, there was a smart rigor on the Thursday. Was the gangrene a kind of erysipelas? an erysipelas gangranosum, gangrenous $a b$ initio?

At any rate, it may be useful to place on record a case which proves, that after a compound fracture, a limb may mortify in an apparently healthy subject above the wound, without its being possible to accuse the treatment. For example, tight bandages have had the blame, when mortification has been found to follow a fractured limb. Here no bandages were applied. If amputation had been performed at first, surely the gangrene which supervened would have been as likely (nay, more likely, with the additional shock of such an operation) to follow the wound made by it, as that made through the integuments by the fractured bones. Indeed, if a fatal mistake could have been made in any direction in such a case as this, I think it would have been easier to err in the direction of commission, than in that of omission. It may be suggested that the delay in procuring skilled assistance for the poor man could scarcely have been in his favour; but how that delay could have brought about precisely the result which followed, I cannot at all see. For my own part, I cannot see how any treatment, whether in the direction of commission or in that of omission, could have either caused or prevented the unusual-the rapidly fatal-train of morbid changes which followed this unfortunate case of compound fracture:-it was a termination which science could have had no reason to expect, and which, even if expected, art could have neither averted nor remedied.

\section{STRANGULATED DIRECT INGUINAL HERNIA IN} A FEMALE.

By John G. Appleton, Esq., Luton.

Strangulated Direct or Internal Inguinal Hernia in a Female: Operation. A Large Inguinal Gland, wide-spread, and overlying the Hernial Sac. Opening the Sac, and division of the Stricture. Recovery, without any unfavourable Symptoms. I was requested to see Phœbe Marlow, aged 39, an unmarried woman, about midday on the 29th 6 mo., 1858. She was not aware that she was the subject of hernia; at that time there were no urgent symptoms. In the absence of the usual physical signs, I suspected that hernia might be the cause of her illness. There was some swelling in the right inguinal region of a glandular character; and some tenderness and pain in manipulating. Although she was ignorant of the nature of her case, she informed me that she had suffered severe pain in that part about six months previously. As the symptoms were not urgent, and constipation of the bowels was characteristic of her habit, I had recourse to laxatives, and enemas with castor oil: the latter were twice exhibited. On the first occasion, with much relief and encouragement to the patient.

On the 2nd of the 7th month, and the fourth day of my attendance, as there was no decided relief, and the symptoms, indeed, were becoming more urgent, I determined to ask a brother practitioner to see the case; and, if necessary, at once to operate. My friend $\mathrm{K}$. Tomson kindly and promptly lent his aid. Obscure in some respects as the case was, an operation appeared to us to offer the only chance of safety for our patient; and therefore, as soon as we had made the necessary arrangements, we proceeded at once to effect it.

On making the usual incisions of an inverted $\mathbf{T}$ over the extended swelling, a large glandular mass was exposed: this, 
for the moment, was embarrassing-in doubt how to proceedwhether to divide the mass or remove it; being firmly persuaded that an hernial protrusion must be found in close contingency, I dissected on the inner side of this mass, and on pushing it on one side, I saw deeply imbedded the object of our search-a knuckle of strangulated intestine, and its sac quite detached from the overlying mass of gland. We judged it best to open the sac, rather than to return it, unopened, into the cavity of the abdomen, where a fatal issue, from constriction at the mouth of the sac, might still result. The opening of the sac was followed by the discharge of some fluid. We were able distinctly to discriminate between the circular character of the blood-vessels of the intestine and the comparatively straight ones of the sac; also, the difference presented in the external character and gloss of the surfaces of the two strictures. After opening the sac, and passing down the finger, I distinctly felt the stricture, directly upwards, in the region of the external ring, and, to all appearances, probably behind it at the edge of the obliquus internus and transversus muscles. On my finger I passed down a common director; and, by its aid, I directed a sheathed hernial knife, known as "Sir Astley Cooper's knife", which, when placed in situ, the sheath was drawn back, and on slightly elevating it, the stricture was divided upwards to the extent, probably, of less than a line. The intestine and sac were immediately returned into the abdomen, a suture was used, and the parts brought together with soap plaister and the ordinary bandage.

She recovered without an untoward symptom; and, with the exception of castor oil, she did not require any medicine.

This case may tend to shew the importance of allowing general indications to have their full weight and influence on our judgment and practice; in the absence even of some physical signs, on which we are accustomed to rely. In this case, the diagnosis was obscure and equivocal.

\section{PATHOLOGICAL CONTRIBUTIONS TO MEDICAL JURISPRUDENCE.}

By William Boyd Mushet, M.B.Lond., late Resident Physician at St. Marylebone Infirmary.

\section{V.-Drowsing}

Case I. A well formed female, aged about 30 , found in the water, and brought, after considerable delay, to the Marylebone Infirmary, on November 16th, 1856. She was cold and lifeless, and the period of immersion could not be ascertained. Warm bath, artificial respiration, sinapisms, friction, and galvanism, were resorted to for above an hour, without producing any signs of animation.

Post Montean Inspection forty-two hours after death. The weather was mild. The countenance was placid and pale. Clear fluid, slightly tinted, escaped from the mouth. Rigor mortis was well marked. The hands were clenched; the nails blue. The pupils were dilated. The tongue was not bitten.

Head. The dura mater was adherent to the calvarium; and the meninges were generally injected. The blood in the sinuses was quite fluid. The brain was natural. No fluid was found in the ventricles.

Chest. A little fluid. was found in the pericardium. The heart was healthy. The right side was flaccid, and filled with dark fluid blood. The left ventricle was contracted, nearly empty. Some dark fluid blood was present in the aorta. The lungs were much engorged, and contained much frothy fluid. Much frothy mucus was also present in the trachea and its divisions. The liver was congested. The kidneys appeared natural; but the right one weighed only an ounce and a half. The stomach was contracted, and pale; it contained three or four ounces of grumous semidigested matter, but no water. The other viscera were healthy.

CASE Ir. A woman, aged 55, was found in the water, and brought to the Marylebone Infirmary, about an hour after. wards, on October 5th, 1856. The countenance was pale; the pupils dilated. There was no foam at mouth. The tongue was protruded, not bitten.

Examination of the Body fifty-two hours afterwards. The weather was warm and damp. Rigor mortis was slightly marked. The face was calm and a little suffused.

Head. The scalp was much congested, and fluid blood escaped on section. Very numerous points of blood were observed on the dura mater. There was slight subarachnoid effusion. The pia mater was not much congested. The brain- substance was natural. There was no fluid in the ventricles Much dark fluid blood escaped from the veins at the base, on section.

Chest. No fluid was found in the pericardium. The heart weighed nine ounces; it was healthy, and of good colour. The right ventricle contained dark fluid blood; the walls were flaccid. The left ventricle was empty; the walls were firmly contracted. The lungs were distended; they were healthy, but very slightly congested posteriorly. The mucous membrane of the trachea and its branches were reddened, and contained tenacious mucus, not frothy. There was no fluid in the pleurre, nor adhesions. A portion of the ileum was darkly discoloured, apparently from post mortem action. A calcified mass was attached to the right Fallopian tube, of the size of a marble. The stomach was contracted; it contained no water, but some semidigested biscuit. The other organs werc healthy, not congested.

Osservations. In the preceding cases, the precise time that the women had been submerged, could not be obtained; but as a bloated and discoloured appearance did not supervene on exposure after many hours, the period in either instance was undoubtedly brief.

In Case I. The appearances were tolerably typical of drowning; i.e., of death from asphyxia.

In Case Ir. The appearances were very slightly pronounced, as there was little or no engorgement of the lungs, and general absence of congestion of the other viscera. The only evidences in favour of the assumption of drowning, were the condition of the heart and pupils, and the calm pale aspect of the deceased, together with the want of proof of any other cause of death, as there was no suspicion of violence, and the organs were remarkably healthy for a woman of fifty-five. The mucus in the air-tubes might have proved of assistance, had the autopsy been performed earlier, as its frothy and aërated character, if existent, might have disappeared in the two days which elapsed previous to the examination of the body.

I here venture to advert to the syncopal (asphyxial?) condition which occasionally ensues after rescue from the water, as -although it has been long since described-it appears to be little known, or apt to be disregarded. As an example, I may mention a young woman, who was brought to me, pale, haggard, but perfectly conscious, after remoral from the canal. When placed in a warm bed, she lapsed into insensibility and apparent death, with cessation of pulse and breathing. Had the patient, under these circumstances, been abandoned to the resources of nature, I feel confident that recovery would have proved hopeless, and that galvanism and artificial respiration, which were promptly employed, were the efficient agents in her restoration to consciousness.

\section{THE MEDICAL COUNCIL.}

\section{BRANCH COUNCIL FOR IREIAND.}

Saturday, January 22nd, 1859.

Presext:-Dr. Apjoln, in the Chair; Dr. Williams, Dr. Stokes, Dr. Smith, Dr. Corrigan; Dr. Maunsell, Registrar.

The minutes of last meeting were approved and signed.

On the motion of Dr. SuITh, seconded by Dr. STokEs, it was resolved-

"That this Council approves of the course taken by the President, in summoning an early meeting of the General Medical Council, for the purpose of considering the difficulties which have arisen on the subject of Registration; and that, as a full meeting of the General Council cannot, under existing circumstances, be expected, it is the opinion of this Council that the General Council should limit its attention to the interpretation of the 1lth Section of Schedule A, and the 46th Clause of the Medical Act."

On the motion of Dr. Corrigan, seconded by Dr. Williads, it was resolved-

"That the Irish Branch Council are of opinion, that on any questions of Registration, not already provided for by the resolutions of the General Council, which may arise in the interval between this time and the meeting of the General Council in August, the powers of the General Council should be delegated to the respective Branch Council of that part of the United Kingdom in which such question may arise."

$$
\text { R. C. WILLIA YTS. }
$$

